\title{
African swine fever: A permanent threat to Indian pigs
}

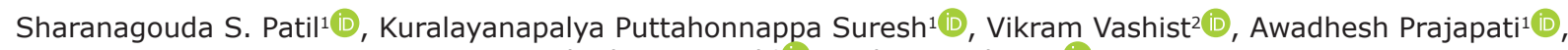
Bramhadev Pattnaik ${ }^{3}$ id and Parimal Roy ${ }^{1}$ (D)

\begin{abstract}
1. Indian Council of Agricultural Research-National Institute of Veterinary Epidemiology and Disease Informatics, Bengaluru, Karnataka, India; 2. Department of Animal Husbandry and Veterinary Services, Shimla, Himachal Pradesh, India; 3. One Health Center for Surveillance and Disease Dynamics, AIPH University, Bhubaneswar, Odisha, India. Corresponding author: Sharanagouda S. Patil, e-mail: ss.patil@icar.gov.in

Co-authors: KPS: sureshkp97@rediffmail.com, VV: vsvashist@gmail.com, AP: avi75prajapati@gmail.com, BP: pattnaikb57@gmail.com, PR: parimalroy580@gmail.com

Received: 01-06-2020, Accepted: 28-09-2020, Published online: 29-10-2020
\end{abstract}

doi: www.doi.org/10.14202/vetworld.2020.2275-2285 How to cite this article: Patil SS, Suresh KP, Vashist V, Prajapati A, Pattnaik B, Roy P (2020) African swine fever: A permanent threat to Indian pigs, Veterinary World, 13(10): $2275-2285$.

\begin{abstract}
India has 9 million pigs, of which $45 \%$ are in the North eastern (NE) states of India. Viral diseases affecting pigs are a major concern of mortality causing huge loss to the pig farmers. One such disease is African swine fever (ASF) that has already knocked the porous borders of NE states of India. ASF is a highly contagious devastating disease of pigs and wild boars causing 100\% mortality. The causative agent African swine fever virus (ASFV) belongs to the genus Asfivirus, family Asfarviridae. Pig is the only species affected by this virus. Soft ticks (Ornithodoros genus) are shown to be reservoir and transmission vectors of ASFV. Transmission is very rapid and quickly engulfs the entire pig population. It is very difficult to differentiate classical swine fever from ASF since clinical symptoms overlap. Infected and in contact pigs should be culled immediately and buried deep, and sheds and premises be disinfected to control the disease. There is no vaccine available commercially. Since its first report in Kenya in 1921, the disease has been reported from the countries in Europe, Russian federation, China, and Myanmar. The disease is a threat to Indian pigs. OIE published the first report of ASF in India on May 21, 2020, wherein, a total of 3701 pigs died from 11 outbreaks (Morbidity - 38.45\% and mortality - 33.89\%) in Assam and Arunachal Pradesh states of India. ASF is non-zoonotic.
\end{abstract}

Keywords: African swine fever, Arunachal Pradesh, Assam, first outbreak, India, North eastern states, pigs, social and economic factors.

\section{Introduction}

African swine fever (ASF) is a highly contagious, devastating disease of pigs and wild boars causing severe mortality. ASF is caused by African swine fever virus (ASFV), a genetically complex virus belonging to the genus Asfivirus of family Asfarviridae [1]. OIE has listed ASF as a notifiable disease. The disease was first described in the early 1900's when the European pig breeds were introduced in Kenya colony [2] and later on disease entered in Europe (Portugal) in 1957 which was controlled quickly, but re-entered Portugal in 1960 and spread to Iberian Peninsula and rest of the Europe [3-7]. Further, progressing to Russian Federation in 2007 and spread to China in 2018, then to Vietnam and Myanmar and to India (Table-1) $[8,9]$. ASFV is spreading transcontinental and has apprehension of becoming a global pig health problem.

India has 9 millions of pigs (Table-2) [10] and North eastern (NE) states of India are having more than $45 \%$ of Indian pig population (Table-3) [10] mostly reared by economically disadvantaged people and pork is their staple food. Further, many NE

Copyright: Patil, et al. Open Access. This article is distributed under the terms of the Creative Commons Attribution 4.0 International License (http://creativecommons.org/licenses/by/4.0/), which permits unrestricted use, distribution, and reproduction in any medium, provided you give appropriate credit to the original author(s) and the source, provide a link to the Creative Commons license, and indicate if changes were made. The Creative Commons Public Domain Dedication waiver (http://creativecommons.org/ publicdomain/zero/1.0/) applies to the data made available in this article, unless otherwise stated. states have porous borders sharing with Tibet, China, Myanmar, and Bangladesh. ASF has already caused a catastrophic effect in pigs in the neighboring countries of India that has cautioned policymakers to be alert in preventing the entry of disease. To safeguard the pig population and to have food security, keeping vigilance on the entry of ASFV in to our territory is of prime importance. A total of 160 new outbreaks were notified from August 21 to September 3, 2020, and that of total ongoing ASF outbreaks worldwide is 7,191 (including 3733 outbreaks in Romania and 1474 outbreaks in Vietnam) [8].

OIE reported on May 21, 2020, a total of 11 outbreaks in Assam and Arunachal Pradesh states of India, wherein 3701 pigs were died due to ASF (Table-4) [11]. Keeping in view of the report on outbreak of ASF in India, this review discusses on the ASF, its epidemiology and transmission, pathogenesis, prevention, and control.

\section{Etiology and Genome Organization}

The causative agent of ASF is ASFV belonging to the genus Asfivirus of the family Asfarviridae. ASFV is the only virus listed in that genus [1].

ASFV is an enveloped virus (Figure-1) [12] having linear genome of double-stranded DNA of length between $170 \mathrm{~kb}$ and $190 \mathrm{~kb}$ in size containing 150-167 ORFs with a conserved central region of about $125 \mathrm{~kb}$ and variable ends (Figure-2) [12]. Five multigene families encoded by these variable regions contribute to the 
Table-1: Reports of ASF in Europe, Asia, and other countries since 1957 [8,9].

\begin{tabular}{|c|c|c|}
\hline S. No & Name of Country & Year of Reporting \\
\hline 1. & Portugal & 1957 and 1960 \\
\hline 2. & Italy & 1967 \\
\hline 3. & Spain & 1969 \\
\hline 4. & Cuba & 1971 and 1980 \\
\hline 5. & France & 1977 \\
\hline 6. & $\begin{array}{l}\text { Malta, Brazil, the Dominican } \\
\text { Republic }\end{array}$ & 1978 \\
\hline 7. & Haiti & 1979 \\
\hline 8. & Belgium & 1985 \\
\hline 9. & Netherlands & 1986 \\
\hline 10. & $\begin{array}{l}\text { Georgia, Armenia, and } \\
\text { Russian Federation (RF) }\end{array}$ & 2007 \\
\hline 11. & Azerbaijan, Iran & 2008 \\
\hline 12. & Ukraine & 2012 \\
\hline 13. & Belarus & 2013 \\
\hline 14. & $\begin{array}{l}\text { Lithuania, Poland, Latvia, } \\
\text { and Estonia }\end{array}$ & 2014 \\
\hline 15. & $\begin{array}{l}\text { Moldova, Irkutsk (RF), Czech } \\
\text { Republic, Romania }\end{array}$ & 2017 \\
\hline 16. & China & August, 2018 \\
\hline 17. & Mongolia & January, 2019 \\
\hline 18. & Vietnam & February, 2019 \\
\hline 19. & Cambodia & March, 2019 \\
\hline 20. & Hong Kong & May, 2019 \\
\hline 21. & North Korea & May, 2019 \\
\hline 22. & Laos & June, 2019 \\
\hline 23. & Philippines & July,2019 \\
\hline 24. & Myanmar & August, 2019 \\
\hline 25. & Indonesia & September, 2019 \\
\hline 26. & South Korea & September, 2019 \\
\hline 27. & Timor-Leste & September, 2019 \\
\hline 28. & Papua New Guinea & March, 2020 \\
\hline 29. & India & May, 2020 \\
\hline
\end{tabular}

Table-2: Details of susceptible pig population in states other than NE states of India [10].

\begin{tabular}{llc}
\hline S. No & State & Pig Population \\
\hline 1. & Andaman and Nicobar & 40,488 \\
2. & Andhra Pradesh & 91,958 \\
3. & Bihar & $3,43,434$ \\
4. & Chhattisgarh & $5,26,901$ \\
5. & Goa & 35,480 \\
6. & Gujarat & 658 \\
7. & Haryana & $1,08,240$ \\
8. & Himachal Pradesh & 2,477 \\
9. & Jammu and Kashmir & 1,215 \\
10. & Jharkhand & $12,76,973$ \\
11. & Karnataka & $3,23,836$ \\
12. & Kerala & $1,03,863$ \\
13. & Madhya Pradesh & $1,64,616$ \\
14. & Maharashtra & $1,61,000$ \\
15. & Odisha & $1,35,162$ \\
16. & Puducherry & 880 \\
17. & Punjab & 52,961 \\
18. & Rajasthan & $1,54,808$ \\
19. & Tamil Nadu & 66,772 \\
20. & Telangana & $1,77,992$ \\
21. & Tripura & $2,06,035$ \\
22. & Uttarakhand & 17,659 \\
23. & Uttar Pradesh & $4,08,678$ \\
24. & West Bengal & $5,40,356$ \\
\hline
\end{tabular}

variability of the virus genome. The ASFV consists a central DNA with a thick protein layer called the core
Table-3: Details of pig population at immediate risk of disease in NE states of India [10].

\begin{tabular}{llc}
\hline S. No & States & Pig population \\
\hline 1. & Arunachal Pradesh & 271,463 \\
2. & Assam & $2,099,000$ \\
3. & Manipur & 235,255 \\
4. & Meghalaya & 706,364 \\
5. & Mizoram & 292,465 \\
6. & Nagaland & 404,695 \\
7. & Sikkim & 27,320 \\
8. & Tripura & 206,035 \\
& Total & $4,242,597$ \\
\hline
\end{tabular}

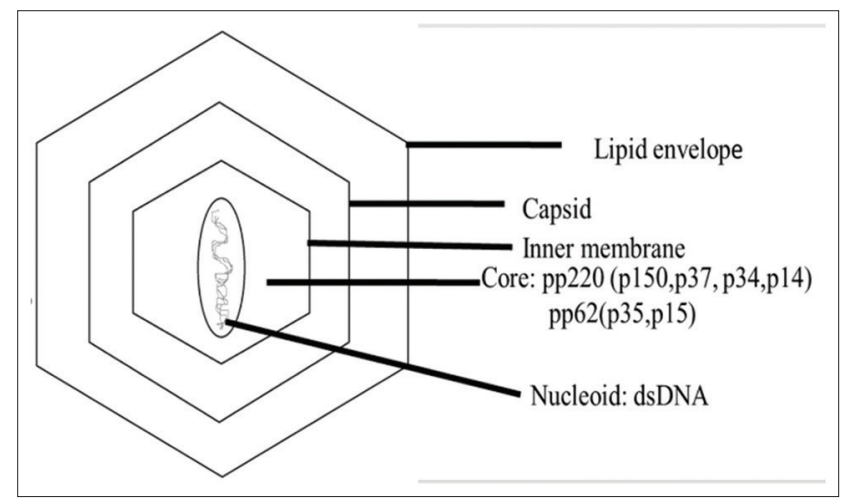

Figure-1: Structure of African swine fever virus [12].

\begin{tabular}{|c|c|c|c|c|}
\hline \multicolumn{4}{|c|}{ ASFV ds DNA genome (170-190 kbp) } \\
\begin{tabular}{|c|ccc|}
\hline ITR & VR & CCR & MGFs \\
\hline & $\longleftarrow 38-477 \mathrm{kpp} \longrightarrow 4$ & VR & ITR \\
\hline
\end{tabular}
\end{tabular}

Figure-2: African swine fever virus genome organization: ITR: Internal terminal repeats, VR: Variable region, MGFs: Multigene families, CCR: Central conserved region [12].

shell, an inner lipoprotein envelope surrounding the core and the icosahedral capsid (p72). The virions on maturity possess a lipid envelope acquired by budding from the plasma membrane. ASFV displays icosahedral symmetry with a diameter of $200 \mathrm{~nm}$. During replication inside host cells, 60 structural proteins related to ASFV or more have been detected [13]. In infected porcine macrophages, 100 viral proteins or more have been identified, of which more than 50 of them react with sera from ASFV recovered pigs [14]. Different genotypes of ASFV have been grouped and recovered from variable severity of disease and there is only one serotype of ASFV detectable by antibody test. There are 24 distinct genotypes classified based on $\mathrm{p} 72$ protein.

Tandem repeat sequences within the B602L gene [15] and the intergenic region between the I73R and I329L genes [16] are sequenced to distinguish subgroups among closely related ASFV. Other genomic regions, namely, E183L (p54), CP204L (p30), and EP402R $(\mathrm{CD} 2 \mathrm{v})$ have been useful spatial epidemiological studies.

\section{Epidemiology}

The spread and transmission of ASF are unique to each continent of Africa, Europe, and Asia. There 
Table-4: Details of first report of African Swine Fever in India [11].

\begin{tabular}{|c|c|c|c|c|}
\hline State & Place & Susceptible & Cases & Deaths \\
\hline \multirow[t]{8}{*}{ Assam } & Pipolguri, Sissiborgaon, Dhemaji, Assam & 2450 & 1897 & 1803 \\
\hline & Kotiyori, Demow, Sivasagar, Assam & 289 & 163 & 117 \\
\hline & Khelowa, Sivasagar, Sivasagar, Assam & 731 & 326 & 298 \\
\hline & Nitai-pukhuri, Demow, Sivasagar, Assam & 642 & 62 & 45 \\
\hline & Bor-Tamuli-II, Pub-Chaiduar, Biswanath, Assam & 689 & 317 & 283 \\
\hline & Gorchuk, Ward No.7, Kamrup Metro, Assam & 153 & 22 & 22 \\
\hline & Bormukoli, Dergaon, Jorhat, Assam & 2580 & 956 & 853 \\
\hline & Total & 7534 & 3743 & 3421 \\
\hline \multirow[t]{5}{*}{ Arunachal Pradesh } & Huchang, Damsite, Naharlagun, Papum Pare, Arunachal Pradesh & 419 & 156 & 103 \\
\hline & Bamin, Bilat, East Siang, Arunachal Pradesh & 653 & 123 & 67 \\
\hline & Pasighat Town, Pasighat, East Siang, Arunachal Pradesh & 1551 & 165 & 101 \\
\hline & D-Sector, Nirjuli, Doimukh, Papum Pare, Arunachal Pradesh & 763 & 12 & 9 \\
\hline & Total & 3386 & 456 & 280 \\
\hline
\end{tabular}

are three cycles of ASF epidemiology such as sylvatic, tick-pig, and domestic, with addition of more factors, that is, soft Ornithodoros spp. ticks, wild African pigs (mainly warthogs), domestic pigs, and pig-derived products such as pork [17]. In the sylvatic cycle, virus is maintained between warthogs and soft ticks, without causing disease in the warthogs [18]. This may be the reason that the virus spilled over to domestic pigs causing disease. In the tick-pig cycle, ticks act as biological reservoir to maintain the virus and infectious agents gets transmitted among domestic pigs [19]. Such type of cycles was seen in parts of sub-Saharan Africa and also during the epidemic on the Iberian Peninsula in the "60s and '70s of the past century [20]. In the domestic cycle, natural reservoirs do not play a role but disease is transmitted in domestic herds from domestic pigs or pig products [21]. The new and fourth cycle of transmission named wild boar-habitat cycle (proposed) reported in some parts of Europe involves Eurasian wild boar, its habitat and their carcasses [22]. This fourth cycle is involving both direct transmissions between wild boar, and indirect transmission through the habitat [23]. Cold and moist climate favors persistency and human movement are the cause of transmission in domestic pigs [24]. Social and economic factors of pig husbandry are also associated with ASF outbreaks in the domestic cycle [25]. It may be hypothesized that the fourth cycle of ASF virus transmission may be attributed to the first outbreak in Assam and Arunachal Pradesh and subsequently domestic cycle might have played in disease transmission between domestic pigs through contaminated pig products/fomites.

\section{Wild boar-habitat cycle}

The wild boar-habitat cycle is having both direct transmission between infected and susceptible wild boar and indirect transmission through carcasses in the area where wild boar habitat. Such areas get contaminated from infected wild boar carcasses, subsequent scavenging by other wild/other pigs [23,26], offer possibilities for both low-dose and high-dose infections, depending on carcass decomposition. It is also observed that the virus may be present in the carcass even if it is a single dead pig for long time and continue to get transmitted to the susceptible animals $[27,28]$. The interface contact between wild boar habitat and domestic pigs is critical in transmission of virus which might have caused first outbreak of ASF in India (hypothetical). Environmental persistence of the virus is favored by a cold and moist climate [22,23,26-28].

\section{Social and economic factors of pig husbandry associ- ated with the domestic cycle}

On confirmation of ASF in Assam and Arunachal Pradesh, culling of all susceptible pigs in- $1 \mathrm{~km}$ radius of epicenter was started. Farmers lost thousands of pigs in this process in addition to those pigs died of disease. As there is no medicine or vaccine, disease got spread rapidly and farmers continue to lose their pigs. Pig-farmers, especially those rearing backyard pigs, had to reduce their holdings and even closing their units of late. Hence, pig husbandry in both states got in disarray and many farmers lost their job and there was no immediate financial support or relief from governments. Consumptions of pork also reduced. Sale of even healthy pigs reduced due to apprehension of the consumers that they may get the disease contracted otherwise it is not [29].

\section{Geographical Distribution of ASF}

World Animal Health Information System of OIE maintains the outbreaks reports of ASF in different countries. Since 2016, a pattern of significant increase in the amount of outbreaks has been identified. ASF is present in the African, European, and most recently, the Asian continent (Table-5) [30]. Most recently there was an outbreak in Papua New Guinea (Oceania) during March, 2020 [8]. It was eradicated in the Americas in the 90's [31]. Since 2016, 30\% of the reporting countries and territories $(60 / 201)$ have identified the disease as present (Table-6) [31]. The disease occurred for the first time in Europe, in Moldova in September 2016, then in June 2017 in Czech Republic, followed by Romania in July 2017 and later on in Hungary, and Bulgaria, in April and August 2018, respectively. A recurrence of the disease in wild boars was reported in Belgium in September 2018 (last event occurred and was resolved in 1985). In Asia, 
Table-5: Cases and losses due to ASF during 2016-2020 in three affected continents [30].

\begin{tabular}{lcccc}
\hline Region & \multicolumn{4}{c}{ Swine } \\
\cline { 2 - 5 } & Outbreak & Susceptible & Cases & $\begin{array}{c}\text { Losses } \\
\text { (dead and } \\
\text { Culled) }\end{array}$ \\
\hline Africa & 128 & $2,13,795$ & 61,459 & 85,539 \\
Europe & 4,271 & $18,59,480$ & $6,25,269$ & $1,383,372$ \\
Asia & 9,928 & $81,07,951$ & $1,15,309$ & $6,733,791$ \\
Total & 14,327 & $1,01,81,226$ & $8,02,037$ & $8,202,702$ \\
\hline
\end{tabular}

Table-6: List of the countries that reported ASF globally [31].

\begin{tabular}{llcl}
\hline S. No & Name of the Country & S. No & $\begin{array}{l}\text { Name of the } \\
\text { Country }\end{array}$ \\
\hline 1 & Angola & 31 & Latvia \\
2 & Belgium & 32 & Lithuania \\
3 & Benin & 33 & Madagascar \\
4 & Bulgaria & 34 & Malawi \\
5 & Burkina Faso & 35 & Mali \\
6 & Burundi & 36 & Moldova \\
7 & Cabo Verde & 37 & Mongolia \\
8 & Cambodia & 38 & Mozambique \\
9 & Cameroon & 39 & Myanmar \\
10 & Central African Republic & 40 & Namibia \\
11 & Chad & 41 & Nigeria \\
12 & China (People's Republic of) & 42 & Poland \\
13 & Congo (Dem. Rep. of) & 43 & Papua New \\
& & & Guinea \\
14 & Congo (Rep. of) & 44 & Philippines \\
15 & Cote D'Ivoire & 45 & Romania \\
16 & Czech Republic & 46 & Russia \\
17 & Estonia & 47 & Rwanda \\
18 & Gambia & 48 & Senegal \\
19 & Ghana & 49 & Serbia \\
20 & Guinea-Bissau & 50 & Slovakia \\
21 & Greece & 51 & Sierra Leone \\
22 & Hong Kong (SAR-PRC), & 52 & South Africa \\
23 & Hungary & 53 & Tanzania \\
24 & Indonesia & 54 & Timor-Leste \\
25 & India & 55 & Togo \\
26 & Italy & 56 & Uganda \\
27 & Lao-PDR & 57 & Ukraine \\
28 & Kenya & 58 & Vietnam \\
29 & Korea (Dem. People's & 59 & Zambia \\
& Rep. of) & & \\
30 & Korea (Rep. of) & 60 & Zimbabwe \\
\hline & & & \\
& & & \\
& & & \\
& & &
\end{tabular}

the disease was reported for the first time in China (People's Republic of) in August 2018, Mongolia in January 2019, and then Vietnam in February 2019, Cambodia in March 2019, and Hong Kong (SARPRC) in May 2019, followed by Laos in June 2019, Myanmar in August 2019, Philippines in July, 2019, Korea (Rep. of) in September 2019, Timor-Leste in September 2019, Indonesia in November 2019, and more recently, Papua New Guinea in March, 2020 (Figure-3), and India in May 2020 (Figure-4) [30].

ASF in one wild boar is considered as a single outbreak which needs a targeted surveillance to be resolved immediately that is practiced in Europe. Africa and Asia have notified outbreaks in domestic pigs mainly, and few cases in wild boar (300 cases reported in Asia since August 2018). During this period, Europe accounted for the majority of outbreaks with 96\% (9756) of all outbreaks, but the highest impact in terms of animal losses was reported in Asia (1711677 animals lost, which is $68 \%$ of the total global reported losses in this period) [30].

The contagiosity, tenacity, and case fatality rate due to ASFV in the population favors its persistence and transmission that becomes hurdle in its eradication programs [32]. Therefore, strict biosecurity measures need to be put in place as per OIE guidelines.

On May 21, 2020, OIE published the first report of ASF in two states of India, namely, Assam and Arunachal Pradesh. There were 4199 cases of ASF in a susceptible pig population of 1092 across five districts and two districts in Assam and Arunachal Pradesh, respectively. 3701 pigs died due to ASF (Table-4 and Figure-4) [11].

\section{Host Range and Transmission}

ASFV infects members Suidae family such as domestic and wild boars, feral pigs, bush pigs, warthogs, forest hog, and Ornithodoros ticks. However, all wild pigs: Warthogs (Phacochoerus aethiopicus), bushpigs (Potamochoerus porcus), and ticks of Ornithodoros genus act as reservoir hosts, maintaining the virus thereby transmitting to the domestic pigs in Africa [33-35]. ASF is non-zoonotic disease. It may be hypothesized that contamination of the habitat by the infected and/ or dead wild pigs in Arunachal Pradesh and Assam or through movement of men and material from the infected habitat might be the possible route of transmission to domestic pigs in India. The role of ticks (Ornithodoros spp.) in transmission of the virus in pigs in India is yet to be established.

\section{Risk Factors}

The most important risk factor associated with occurrence of disease in NE states of India is that many states share a porous border with neighboring countries such as Myanmar, Bangladesh, Tibet, and China wherein ASF is reported. There are no restrictions in the movement of men and material including piglets without any health records along the borders of Myanmar, Bangladesh, and Tibet. Other factors which may facilitate virus transmission such as location of pig farms, densely populated stys, seasons/marshy areas favoring breeding of ticks, improper disposal of carcass, slaughtering of pigs by farm side, sale of sick pigs, unknown source of replacement stock, feeding of swill, and unrestricted movement of men and materials between farms, vicinity of farm to forest areas wherein wild pigs come in contact with farm pigs $[36,37]$. Role of ticks in the transmission of ASF in India is yet to be reported.

\section{ASF Transmission in India [11]}

A total of 11 outbreaks were reported in two states, namely, Arunachal Pradesh and Assam. The 


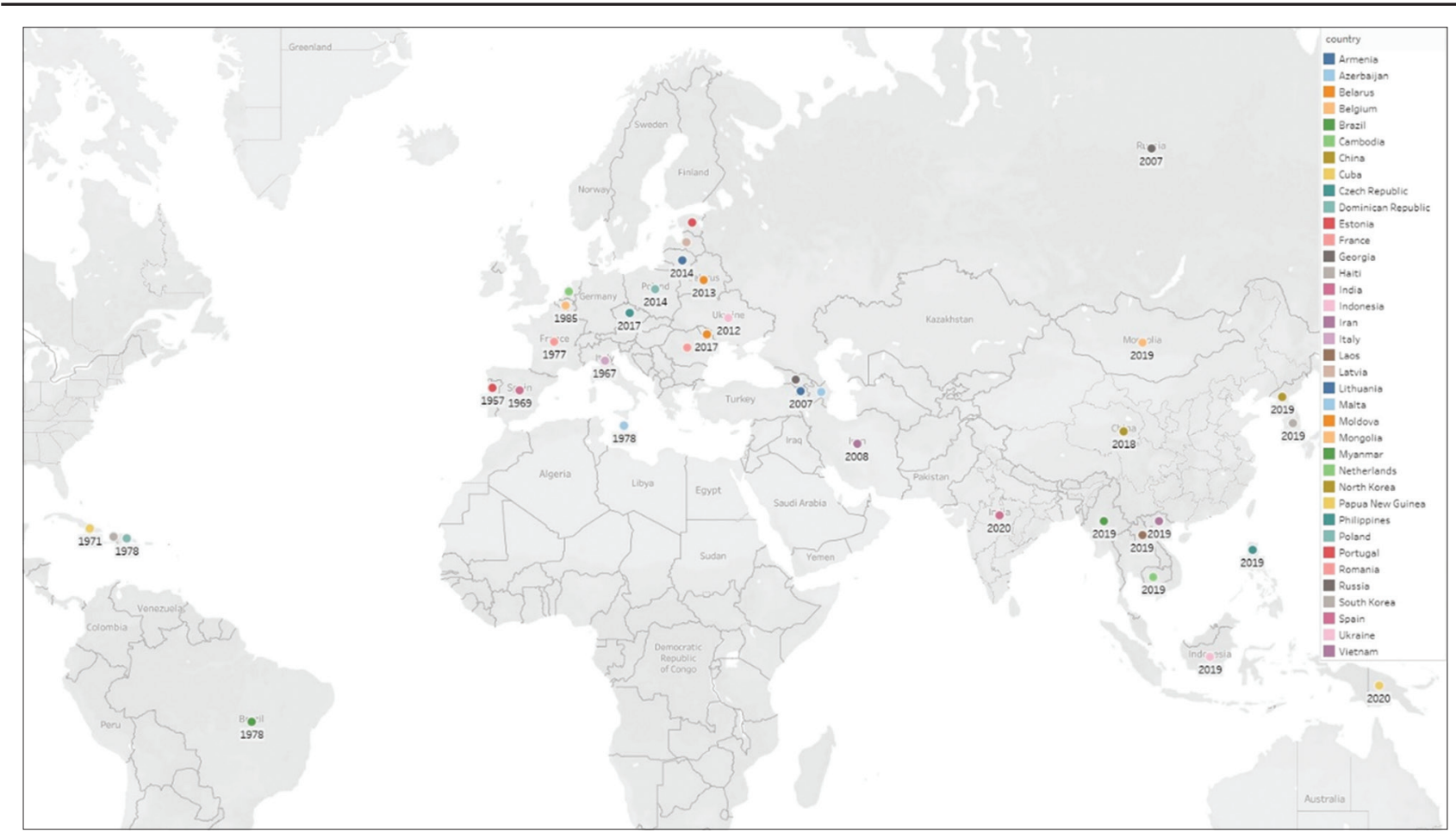

Figure-3: Countries that have reported African swine fever in Europe, Asia and other continents since 1957 [8,9].

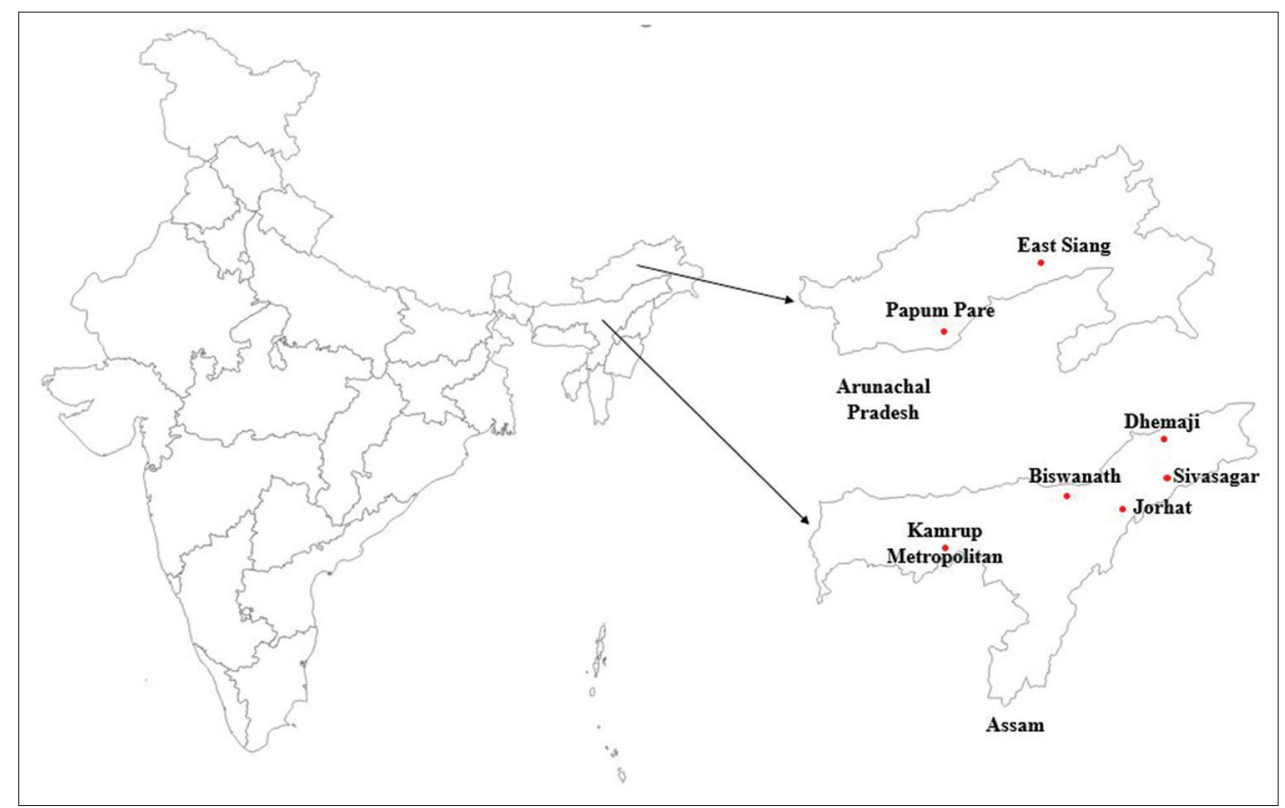

Figure-4: Locations of first reports of African swine fever in Arunachal Pradesh and Assam in India [11].

date of start of first outbreak was January 26, 2020, and was continuing till April 24, 2020. There were four outbreaks in Arunachal Pradesh and seven in Assam.

\section{Arunachal Pradesh}

ASF outbreak reported in two districts, namely, East Siang and Papum Pare which are located $299 \mathrm{~km}$ (by road) apart. It is contemplated that the first outbreak of ASF was started in Pasighat town area on January 26, 2020, and then in Bilat area of East Siang district. The exact cause of origin of occurrence of disease could not be arrived as we could not make a visit to the site due to pandemic.
It was learnt that local people could notice the death of wild boars in the drainages/rivulets nearby areas of Pasighat region that could have contaminated the habitat. Pasighat is located $25 \mathrm{~km}$ (by road) away from Bilat region. Simultaneously, disease was transmitted to Naharlagun region of Papum Pare district which is located $233 \mathrm{~km}$ away from Bilat region of East Siang. Approximately, after 3 months of appearance of disease in Naharlagun region, disease was transmitted to Nirjuli/Doimukh area of Papum Pare which is $8 \mathrm{~km}$ away from Naharlagun region. It may be hypothesized that movement of men and material between the regions along with transportation of 
piglets to these two regions might have caused the spread of disease.

\section{Assam}

A total of seven outbreaks of ASF were reported in the state between February 24, 2020, and April 10, 2020. Since its first outbreak in Arunachal Pradesh region, after 1 month, the disease was reported in Dhemaji region (February 24, 2020) of Assam. Subsequently, after a week, disease was seen in Sivasagar region (March 7, 2020), then into Biswanath (March 20, 2020), again into another region of Sivasagar (March 23, 2020), and simultaneously (April 2, 2020) into different regions of Kamrup Metro and Sivasagar districts. On April 10, 2020, one more outbreak was seen in Jorhat districts of Assam. Sivasagar district of Assam reported three outbreaks in different regions within 26 days. It was noticed that the spread of disease was more rapid to different regions/districts which may be due to the panic among the farmers thereby opting for distress sale of pigs at less rates and also buying of pigs by other farmers/ consumers at lower prices.

It may be hypothesized that within 3 months of period, all 11 outbreaks have happened as one cluster. Role of ticks in transmission of disease need to be established, otherwise fourth cycle (proposed), namely, wild boar-habitat cycle [22] might have played (hypothetical) role in outbreak of ASF in these two districts.

\section{Clinical Signs and Gross Pathology}

There are different forms of clinical presentations of ASF, namely, peracute, acute, subacute, and chronic associated with virulence of virus Yoo et al. [38]. ASF virus isolates are classified as highly virulent, moderately virulent, and low virulent Pan and Hess [39]. The incubation period of the disease vary from 4 to 19 days. Mortality rate depends on virulence of virus ranging from $100 \%$ in disease caused by highly virulent to $<20 \%$ in chronic forms caused by low virulent virus [26].

Peracute form of ASF caused by highly virulent strains of ASFV causes death within 4 days of infection without any gross lesions. Such form of disease is seen when virus enters into naïve pig farms. Infected pigs show high fever (up to $42^{\circ} \mathrm{C}$ ), anorexia, lethargy, and sudden death and some pigs may show respiratory signs due to high temperature [40].

Acute form of ASF is caused by highly virulent virus and characterized by high fever $\left(40-42^{\circ} \mathrm{C}\right)$, with mortality rate reaching up to $100 \%$ within $4-9$ day's post-infection [41]. The infected pigs show anorexia, lethargy, inactive, and bunch up together [42]. Bluishpurpled areas/hemorrhagic spots on ears, abdomen, hind legs, and generalized reddening of skin (chest, abdomen, tail, and leg), blood from nose/mouth, and bloody feces [26]. Lesions in dead pigs show pulmonary edema, hyperemic splenomegaly, extensive hemorrhages of internal organs, intensive necrosis of lymphoid tissue, petechial hemorrhages in the lungs, and urinary bladder and kidneys [43]. The other most important lesion described in acute ASF is multifocal hemorrhagic lymphadenitis. Lymph nodes can have multifocal or extensive hemorrhages that can produce a marbled appearance [42]. It may be contemplated after observing the mortality patterns in Assam and Arunachal Pradesh that acute form of the diseases was seen in pigs.

Subacute form of ASF is produced by moderately virulent strain and the clinical signs produced are milder ones which may overlap with other conditions in pigs and may not lead to suspicion of ASF. The clinical signs exhibited are similar to acute form of disease but less marked. Illness may last for 30-45 days. Most cases recover after intermittent fever up to 1 month. Mortality may vary from $30 \%$ to $70 \%$ and pigs may die after 20 days after infection [26,43]. The vascular changes observed in subacute forms of ASF are mainly hemorrhage and edema and are more intense than those reported in the acute form of the disease $[44,45]$. The pigs after recovery may excrete the virus up to 6 weeks [40]. There are two different stages that cause death of affected pigs: In the intense thrombocytopenia/leukopenia phase or in the recovery phase when hemorrhages appear due to erythrodiapedesis by vasodilation, especially in young animals $[45,46]$.

Chronic form of ASF is produced by low virulent strains $[40,42]$ with low mortality $(20 \%)$ and no vascular lesions. This type of disease is seen in Spain, Portugal, and also in Dominican Republic. The chronic form may have arisen due to evolution of ASF virus isolates used in the vaccine trials carried out in Iberian Peninsula [40]. Various signs such as loss of weight, reddening of skin, growth retardation in growing pigs, irregular peaks of temperature, joint swellings, and respiratory signs. These viruses are non-haemadsorbing strains, but some animals develop discrete lesions in the lungs or on the skin over bony protrusions and joint swellings [26]. Recovered and infected pigs both by high and low virulent virus act as persistent carriers which transmit the disease in disease-free zones $[20,41,43]$.

Diseases that are to be differentiated from ASF are Classical swine fever, Highly Pathogenic-Porcine Reproductive and Respiratory Syndrome, Aujeszky's disease, Swine Erysipelas, Septicemic Salmonellosis, Porcine Dermatitis and Nephropathy Syndrome [40].

\section{Pathogenesis}

ASF is a complex disease causes immunodeficiency in affected pigs [47] The virus replicates (Figure-5), after entering through oral-nasal route, initially in the tonsils or regional lymph nodes [48]. The cellular receptors and virus ligands still remains elusive [49]. Virus spreads to secondary organs of replication through blood (viremia) or lymph within 2-3 day's post-infection [50], and later to other organs where it can replicate [45]. ASF virus targets mainly monocytes and macrophages [51], UK and 


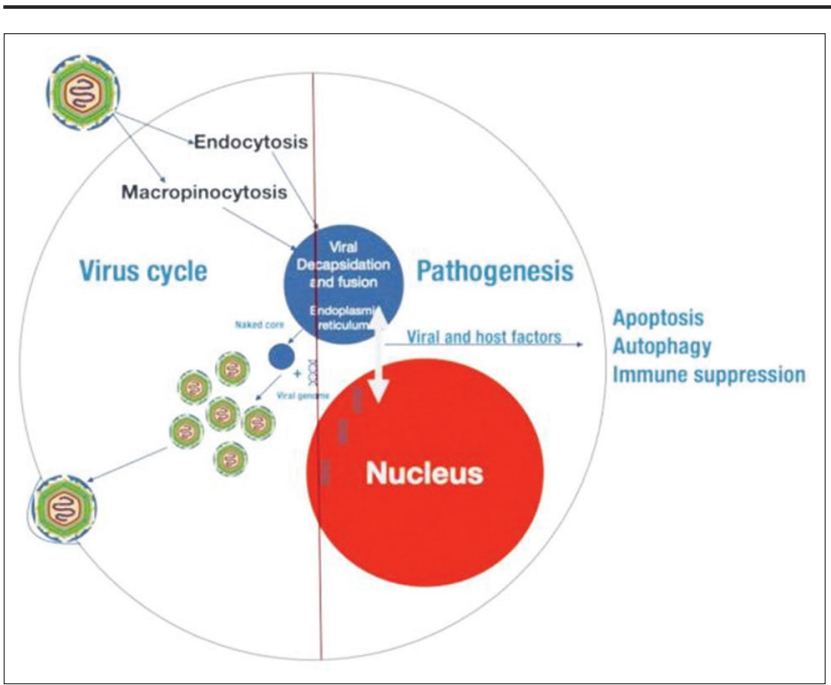

Figure-5: Replication cycle of African swine fever virus in a host's cell.

NL genes of ASFV play a pivotal role in virulence and pathogenesis along with 8DR which is responsible for hemadsorption (HAD) property of HAD isolates which cause acute disease as compared to non-HAD [52]. The infected monocyte-macrophage appears swollen. There will be a necrosis in the infected cells and virions are released by budding, and can be observed free in the blood, lymph, and the interstitial tissue [53]. ASFVinduced apoptosis or necrosis causes the destruction of monocytes-macrophages. In acute form, lymphoid organs including spleen, lymph nodes, thymus, and tonsils are destroyed [51] and major population of $\mathrm{B}$ and $\mathrm{T}$ lymphocytes and macrophages undergo cell death [51]. Hemorrhagic or hyperemic splenomegaly, petechial and ecchymotic hemorrhages in multiple organs, pulmonary edema, and disseminated intravascular coagulopathy are the changes observed [26].

In subacute ASF, additionally, a more marked edema, ascites, and hydropericardium are observed [54]. Lymph nodes associated with kidney and gastrohepatic regions without fixed vascular macrophage population have severe hemorrhages [45]. Pulmonary intravascular macrophages get infected with virus causing hemorrhages and edema [53].

\section{Diagnosis}

ASFV infection is very difficult to differentiate from CSFV infection either by clinical or post-mortem examination. Hence, it is essential to confirm the ASFV infection through laboratory diagnosis only. The laboratory diagnostic techniques are directed to detect the agent or immune response to agent. The samples to be sent for laboratory diagnosis are blood, serum, and tissues (spleen, lymph nodes, bone marrow, lung, tonsil, and kidney) [38]. The samples should preferably be transported on ice to laboratory.

\section{Detection of the agent}

i. Virus isolation: Primary leukocyte culture or porcine bone marrow cells are commonly used for isolation of virus [26]. ii. HAD test [55]: Virus isolation in macrophages and HAD is the gold standard for identification of ASFV required for the first detection of ASF in disease-free regions or in the primary outbreak areas. 8DR protein of ASFV is responsible for HAD property wherein virus in macrophages binds to pig erythrocytes causing rosette [26] and some viruses are non-HAD. HAD ASFV are pathogenic and non-HAD ASFV are non-pathogenic or avirulent [38]. HAD test is cumbersome and is practiced in reference laboratories only. A detailed test protocol is available in OIE manual [43]. The HAD phenotypes of ASFV readily show CPE, where care should be taken while interpreting the non-HAD phenotypes of ASFV which also produce CPE but do not hemadsorb [56].

iii. Fluorescent antibody test (FAT): Directly can be used on field samples or those inoculated at the laboratory. Alone can serve as only presumptive diagnostic test along with clinical sings and typical lesions of ASFV [14].

iv. ELISA for antigen detection: The sensitivity of the assays is lower than polymerase chain reaction (PCR) or HAD. Hence, usually this method is not recommended for confirmatory diagnosis.

v. Conventional PCR: Should be performed using primer sets targeting the most conserved genome parts so as identify and detect a wide range of ASFV isolates of all the known genotypes [57].

vi. Real-time PCR: The technique is highly sensitive and less time-consuming and even can be used on samples which are not fit for virus isolation or antigen detection assays. The OIE recommends to follow quantitative PCR using real-time PCR primers and probes [34,58].

\section{Detection of immune response to agent or serologi- cal tests}

The serological tests are the most commonly used diagnostic tests because of their simplicity, relatively low cost, and less specialized equipment's are needed. The serological tests are also more relevant because as on date there are no commercially available vaccines and hence vaccination is not practiced. Which means presence of antibodies against ASFV indicates either disease is ongoing or it affected the herd. The antibodies appear as early as 7-10 days and can persist for several months or even years $[26,56]$.

i. ELISA: The indirect ELISA [59] which is suitable for testing both serum and plasma. However, positive samples should be confirmed by indirect FAT (IFAT), indirect immunoperoxidase test (IPT) or immunoblotting. Different types of ELISA (competitive or blocking) commercially available are being used for the detection of antibodies against ASFV infection [56].

ii. IPT: The test developed by Gallardo et al. [60] is recommended by OIE.

iii. IFAT: The protocol developed by SánchezVizcaíno [61] is recommended by OIE. IPT and 
IFAT are a confirmatory test for sera from areas that are free from ASF and are positive in the ELISA, and for sera from endemic areas that give an inconclusive result in the ELISA.

\section{Immunoblotting test}

The procedure standardized by Pastor [62] is used as alternate to IFAT and IPT to confirm equivocal results with individual sera. The tests perform better than other tests even in the detection of weak positive samples for ASFV antibodies.

\section{Prevention and Control}

\section{Antiviral agents/compounds}

Antiviral compounds/molecules can be of use in targeting virus-specific enzymes that play a role in viral replication including DNA polymerases of ASFV and some of the researchers have successfully used such drugs in preventing ASFV replication in vitro [63]. Sodium phenylbutyrate has shown inhibition of ASFV replication and viral late protein synthesis [64], Resveratrol and oxyresveratrol have shown an antiviral effect on ASFV in cell culture [65]. 5-(Perylen-3-ylethynyl)-arabino-uridine and 5-(Perylen-3-ylethynyl) uracil-1-acetic acid against ASFV have shown dose-dependent inhibitory effect on ASFV infection in Vero cells [66]. All these experiments were conducted in vitro and are to be validated in pigs.

\section{Biosafety and biosecurity measures}

Biosafety at farm level is to be practiced. Persons/ labors handling the infected pigs should take all biosafety precautions such as wearing of protective equipment such as aprons, spectacles, gloves, and gumboots and should not visit the other sheds. Gumboots should be washed with $2 \%$ sodium hydroxide immediately after use and various commercial products of disinfectants are available in the market [67].

Biosecurity at farm and village/surrounding regions is to be practiced. Isolation, restriction of movement and sanitation (cleaning and disinfection) has controlled the spread of ASFV [68]. Rapid culling of all infected and in-contact pigs and proper disposal of cadavers, litter, and waste food is essential. All these things should be buried deeply in the vicinity over layered with lime and salt, not to transport to distant places to avoid spillage. Thorough cleaning (with water) of farm/infected area and disinfection (Disinfection may be carried out with $2 \%$ sodium or calcium hypochlorite/sodium hydroxide or a detergent-based virucidal agent), [67] if tick population is high, one can use acaricide depending on the need. Farm utensils should be cleaned with detergents and washed properly. Creating awareness among the animal health workers about the disease, training them in early recognition, collection, and dispatch of suspected clinical samples, and intimation to the nearest dispensary are important steps in the field of healthcare system [69].
Table-7: Details of attenuated vaccines against ASF under experimental stage [70].

\begin{tabular}{lcl}
\hline S. No & $\begin{array}{c}\text { Experimental Vaccines } \\
\text { using different genotypes }\end{array}$ & Target gene (s) \\
\hline 1. & $*+[72]$ & A238L \\
2. & $*+[72]$ & A224L \\
3. & $*+[72]$ & EP153R \\
4. & $*+[73,74]$ & MGF360/530/505 \\
5. & $*+[75]$ & DP148R \\
6. & $* \$[76]$ & CD2v (EP402R) \\
7. & $\wedge+[77]$ & $9 G L$ and UK \\
8. & $\wedge-[78]$ & TK \\
9. & $\wedge-[79]$ & $9 G L$ and MGFs \\
10. & $+[80]$ & $9 G L$ \\
11. & $\wedge+[81]$ & MGF360/505 \\
12. & $\wedge+[82]$ & $9 G L$ \\
13. & $*+[83]$ & Naturally attenuated \\
14. & $*+[84,85]$ & Naturally attenuated \\
15. & $\wedge \#[86]$ & Low virulent \\
16. & $*+[87]$ & Cell culture-adapted \\
\hline
\end{tabular}

*Genotype I; ^Genotype II; +Protection against

homologous challenge; ${ }^{\text {PPotection against homologous }}$ and heterologous challenge; -No protection; "Protection against virulent challenge

\section{Vaccines}

At present, there are no vaccines available commercially. Testing of infected and in contact pigs, culling all positive reactors are the only way of preventing the spread of infection, but that eliminates large number of pigs in the locality leading to economic losses to pig farmers. DNA vaccines that contain ASFV genome constructs devoid of CD2v, p54, and p30 have been tried and given limited protection in a population. The development of vaccines against ASF is difficult because of complex nature of virus with its large number of proteins evading host-immune system. Live-attenuated candidate vaccine strains have been generated from virulent strains and are under field trials (Table-7) [70]. Another obstacle in the ASFV propagation is non-availability of a permanent cell lines which can sustain its multiplicity and production in large scale [71].

\section{Conclusion}

ASF is a highly contagious disease of pigs and wild boars causing $100 \%$ mortality leading to huge economic loss to pig farmers. There is no vaccine available commercially. Affected and in contact pigs are to be culled and buried deep. The infected sheds and premises need to be cleaned and disinfected thoroughly and restocking can be done 4 months later from known source of healthy farms. The ASF is reported from neighboring countries of NE states of India and may enter at any time that can persistently remain in our pigs. Therefore, one need to be vigilant and alert.

While submitting this manuscript, OIE reported first occurrence of ASF in two states of India, namely, Assam and Arunachal Pradesh on May 21, 2020. 


\section{Authors' Contributions}

SSP conceptualized, designed, collected all relevant literatures, and prepared the first draft. KPS collected ASF outbreak data and prepared the distribution map. VV prepared the topic relevant to epidemiological aspect of ASF. AP assisted in formatting the manuscript and arranging references as per the style. BP provided the information on studies related to ASF vaccines. PR edited the whole manuscript and provided the inputs required for finalizing the manuscript. All authors have reviewed the final manuscript and approved the same.

\section{Acknowledgments}

The authors would like to thank the Director, ICAR-NIVEDI, Bengaluru, India, for providing constant encouragement and support in preparation of this manuscript. Thanks are due to Dr. G.B. Manjunatha Reddy, Scientist, for providing critical input of ASF pathogenesis. We also thank Mr. Srikanth Gowda, Mr. Darshan and Ms. K N Mandara for their assistance in preparation of the manuscript.

\section{Competing Interests}

The authors declare that they have no competing interests.

\section{Publisher's Note}

Veterinary World remains neutral with regard to jurisdictional claims in published map and institutional affiliation.

\section{References}

1. Dixon, L.K., Escribano, J.M., Martins, C., Rock, D.L., Salas, M.L. and Wilkinson, P.J. (2005) Asfarviridae. In: Fauquet, C.M., Mayo, M.A., Maniloff, J., Desselberger, U. and Ball, L.A., editors. Virus Taxonomy. $8^{\text {th }}$ Report of the International Committee on Taxonomy of Viruses. Elsevier Academic Press, London. p135-143.

2. Montgomery, R.E. (1921) On a form of swine fever occurring in British East Africa (Kenya Colony). J. Comp. Pathol. Ther., 34(3): 159-191.

3. Sanchez-Vizcaino, J.M., Mur, L. and Martinez-Lopez, B. (2012a) African swine fever: An epidemiological update. Transbound. Emerg. Dis., 1(Suppl 59): 27-35.

4. Biront, P., Castryck, F. and Leunen, J. (1987) An epizootic of African swine fever in Belgium and its eradication. Vet Rec., 120(18): 432-434.

5. Terpstra, C. and Wensvoort, G. (1986) African swine fever in the Netherlands. Tijdschr Diergeneeskd, 111(8): 389-392.

6. Swaney, L.M., Lyburt, F., Mebus, C.A., Buonavoglia, C. and Orfei, A. (1987) Genome analysis of African swine fever virus isolated in Italy in 1983. Vet. Microbiol., 14(2): 101-104.

7. Wilkinson, P.J., Lawman, M.J. and Johnston, R.S. (1980) African swine fever in Malta, 1978. Vet Rec., 106(5): 94-97.

8. World Organization for Animal Health. (2020a) African Swine Fever (ASF) Report No. 52: August 21-September 03, 2020. World Animal Health Information Department, World Organization for Animal Health, Paris, France.

9. Food and Agriculture Organization. (2018) African swine fever threatens Peoples Republic of China. Animal Health Risk Analysis, Assessment No. 5. Food and Agriculture Organization, Rome, Italy.

10. Livestock Census. (2019) Department of Animal Husbandry and Dairying (DAHD). GOI, New Delhi, India.

11. World Organisation for Animal Health. (2020b) Available from: https://www.oie.int/wahis 2/public/wahid.php/ Reviewreport/Review?page_refer=MapFullEventReport\&reportid=34283. Retrieved on 19-10-2020.

12. Andres, G., Simon-Mateo, C. and Vinuela, E. (1997) Assembly of African swine fever virus: Role of polyprotein pp220. J. Virol., 71(3): 2331-2341.

13. Alejo, A., Matamoros, T., Guerra, M. and Andres, M. (2018) A proteomic atlas of the African swine fever virus particle. J. Virol., 92(23): e01293-18.

14. Sanchez-Vizcaino, J.M. and Arias, M. (2012b) African swine fever. In: Zimmerman, J.J., Karriker, L.A., Ramirez, A., Schwartz, K.J. and Stevenson, G.W., editors. Disease of Swine. $1^{\text {th }}$ ed. Wiley-Blackwell, Ames, USA. p396-404.

15. Gallardo, C., Mwaengo, D.M., Macharia, J.M., Arias, M., Taracha, E.A. and Soler, A. (2009) Enhanced discrimination of African swine fever virus isolates through nucleotide sequencing of the p54, p72, and pB602L (CVR) genes. Virus Genes, 38(1): 85-95.

16. Gallardo, C., Fernández-Pinero, J., Pelayo, V., Gazaev, I., Markowska-Daniel, I., Pridotkas, G., Nieto, R., FernándezPacheco, P., Bokhan, S., Nevolko, O., Drozhzhe, Z., Pérez, C., Soler, A., Kolvasov, D. and Arias, M. (2014) Genetic variation among African swine fever genotype II viruses, eastern and central Europe. Emerg. Infect. Dis., 20(9): 1544-1547.

17. Costard, S., Mur, L., Lubroth, J., Sanchez-Vizcaino, J.M. and Pfeiffer, D.U. (2013) Epidemiology of African swine fever virus. Virus Res., 173(1): 191-197.

18. Plowright, W., Thomson, G.R. and Neser, J.A. (1994) African swine fever. In: Coetzer, J.A.W., Thomson, G.R., Tustin, R.C., editors. Infectious Diseases in Livestock with Special Reference to Southern Africa. Vol. 1. Oxford University Press, Cape Town. p567-592.

19. Wilkinson, P.J. (1984) The persistence of African swine fever in Africa and the Mediterranean. Prev. Vet. Med., 2(1-4): 71-82.

20. Boinas, F.S., Wilson, A.J., Hutchings, G.H., Martins, C. and Dixon, L.J. (2011) The persistence of African swine fever virus in field-infected Ornithodoros erraticus during the ASF endemic period in Portugal. PLoS One., 6(5): e20383.

21. Penrith, M.L. and Vosloo, W. (2009) Review of African swine fever: Transmission, spread and control. J. S. Afr. Vet. Assoc., 80(2): 58-62.

22. Chenais, E., Ståhl, K., Guberti, V. and Depner, K. (2018) Identification of wild boar-habitat epidemiologic cycle in African swine fever epizootic. Emerg. Infect. Dis., 24(4): 810.

23. Probst, C., Gethmann, J., Amler, S., Globig, A., Knoll, B. and Conraths, F.J. (2019) The potential role of scavengers in spreading African swine fever among wild boar. Sci. Rep., 9(1): 11450.

24. Chenais, E., Boqvist, S., Sternberg-Lewerin, S., Emanuelson, U., Ouma, E., Dione, M., Aliro, T., Crafoord, F., Masembe, C. and Stahl, K. (2017a) Knowledge, attitudes and practices related to African swine fever within smallholder pig production in Northern Uganda. Transbound. Emerg. Dis., 64(1): 101-115.

25. Chenais, E., Boqvist, S., Emanuelson, U., von Bromssen, C., Ouma, E., Aliro, T., Masembe, C., Stahl, K. and SternbergLewerin, S. (2017b) Quantitative assessment of social and economic impact of African swine fever outbreaks in Northern Uganda. Prev. Vet. Med., 144(1): 134-148.

26. Beltrán-Alcrudo, D., Arias, M., Gallardo, C., Kramer, S. and Penrith, M.L. (2017) African Swine Fever: Detection and Diagnosis a Manual for Veterinarians. FAO Animal Production and Health Manual No. 19. Food and Agriculture Organization of the United Nations, Rome. p88.

27. European Food Safety Authority. (2014) Evaluation of possible mitigation measures to prevent introduction and spread of African swine fever virus through wild boar. EFSA J., 12(3): 3616. 
28. Depner, K., Gortazar, C., Guberti, V., Masiulis, M., More, S. and Oḷševskis, E. (2017) Epidemiological analyses of African swine fever in the Baltic States and Poland. EFSA J., 15(11): 5068

29. Cappai, S., Rolesu, S., Coccollone, A, Laddomada, A. and Loi, F. (2018) Evaluation of biological and socio-economic factors related to persistence of African swine fever in Sardinia. Prev. Vet. Med., 152(1): 1-11.

30. World Organization for Animal Health. (2020c) African Swine Fever (ASF) Report No. 47: 2016-2020. World Animal Health Information Department, World Organization for Animal Health, Paris, France.

31. World Organization for Animal Health. (2020d) African Swine Fever (ASF) Report No. 17: 2016-019. World Animal Health Information Department, World Organization for Animal Health, Paris, France.

32. Costard, S., Wieland, B., De Glanville, W., Jori, F., Rowlands, R., Vosloo, W. and Dixon, L.K. (2009) African swine fever: How can global spread be prevented? Philos. Trans. R. Soc. B Biol. Sci., 364(1530): 2683-2696.

33. Chenais, E., Depner, K., Guberti, V., Dietze, K., Viltrop, A. and Stahl, K. (2019) Epidemiological considerations on African swine fever in Europe 2014-2018. Porcine Health Manag., 5(6): 1-10.

34. King, D.P., Reid, S.M., Hutchings, G.H., Grierson, S.S., Wilkinson, P.J., Dixon, L.K., Bastos, A.D.S. and Drew, T.W. (2003) Development of a TaqMan ${ }^{\circledR}$ PCR assay with internal amplification control for the detection of African swine fever virus. J. Virol. Methods, 107(1): 53-61.

35. Sanchez-Vizcaino, J.M., Martinez-Lopez, B., MartinezAviles, M., Martins, C., Boinas, B., Vial, L., Michaud, V., Jori, F., Etter, E., Albina, E. and Roger, F. (2009) Scientific Review on African Swine Fever. CFP/EFSA/ AHAW/2007/02, Report. p1-141.

36. Awosanya, E.J., Olugasa, B., Ogundipe, G. and Grohn, Y.T. (2015) Sero-prevalence and risk factors associated with African swine fever on pig farms in Southwest Nigeria. BMC Vet. Res., 11(1): 133-144.

37. Huang, Z.Y.X., Langevelde, F., Honer, K.J., Naguib, M. and Boer, W.F. (2017) Regional level risk factors associated with the occurrence of African swine fever in West and East Africa. Parasit. Vectors, 10(1): 16-24.

38. Yoo, D., Kim, H., Lee, J.Y. and Yoo, H.S. (2020) African swine fever: Etiology, epidemiological status in Korea, and perspective on control. J. Vet. Sci., 21(2): 38.

39. Pan, I.C. and Hess, W.R. (1984) Virulence in African swine fever: Its measurement and implications. Am. J. Vet. Res., 45(2): 361-366.

40. Sanchez-Vizcaino, J.M., Mur, L., Gomez-Villamandos, J.C. and Carrasco, L. (2015) An update on the epidemiology and pathology of African swine fever. J. Comp. Pathol., 152(1): 9-21.

41. Gallardo, C., Soler, A., Nieto, R., Sánchez, M.A., Martins, C., Pelayo, V., Carrascosa, A., Revilla, Y., Simón, A., Briones, V., Sánchez-Vizcaíno, J.M. and Arias, M. (2015) Experimental transmission of African swine fever (ASF) low virulent isolate NH/P68 by surviving pigs. Transbound. Emerg. Dis., 62(6): 612-622.

42. Salguero, F.J. (2020) Comparative pathology and pathogenesis of African swine fever infection in swine. Front. Vet. Sci., 19(7): 282-295.

43. World Organisation for Animal Health. (2019) Available from: https://www.oie.int/fileadmin/Home/eng/Health standards/tahm/3.08.01 ASF.pdf. Retrieved on 19-10-2020.

44. Gomez-Villamandos, J.C., Hervas, J., Mendez, A., Carrasco, L., de Las Mulas J.M., Villeda, C.J., Wilkinson, P.J. and Sierra, M.A. (1995) Experimental African swine fever: Apoptosis of lymphocytes and virus replication in other cells. J. Gen. Virol., 76(Pt 9): 2399-2405.

45. Gomez-Villamandos, J.C., Bautista, M.J., SanchezCordon, P.J. and Carrasco, L. (2013) Pathology of African swine fever: The role of monocyte-macrophage. Virus Res.,
173(1): 140-149

46. Gomez-Villamandos, J.C., Bautista, M.J., Carrasco, L., Chacon, M., De Lara, F., Hervás, J., Wilkinson, P.J. and Sierra, M.A. (1998) Thrombocytopenia associated with apoptotic megakaryocytes in a viral haemorrhagic syndrome induced by a moderately virulent strain of African swine fever virus. J. Comp. Pathol., 118(1): 1e13.

47. Salguero, F.J., Sanchez-Cordon, P.J., Nunez, A., de Marco, M.F. and Gomez-Villamandos, J.C. (2005) Pro inflammatory cytokines induce lymphocyte apoptosis in acute African swine fever infection. J. Comp. Pathol., 132(4): 289-302.

48. Greig, A. (1972) Pathogenesis of African swine fever in pigs naturally exposed to the disease. J. Comp. Pathol., 82(1): 73-79.

49. Karger, A., Pérez-Núñez, D., Urquiza, J., Hinojar, P., Alonso, C, Freitas, F.B., Revilla, Y., Le Potier, M.F. and Montoya, M. (2019) An Update on African Swine Fever Virology. Viruses, 8(9): 864-878.

50. Colgrove, G.S., Haelterman, E.O. and Coggins, L. (1969) Pathogenesis of African swine fever in young pigs. Am. J. Vet. Res., 30(8): 1343-1359.

51. Salguero, F.J., Ruiz-Villamor, E., Bautista, M.J., SánchezCordón, P.J., Carrasco, L. and Gómez-Villamandos, J.C. (2002) Changes in macrophages in spleen and lymph nodes during acute African swine fever: Expression of cytokines. Vet. Immunol. Immunopathol., 90(1-2): 11-22.

52. Nogal, M.L., de Buitrago, G.G., Rodriguez, C., Cubelos, B., Carrascosa, A.L., Salas, M.L. and Revilla, Y. (2001) African swine fever virus IAP homologue inhibits caspase activation and promotes cell survival in mammalian cells. J. Virol., 75(6): 2535-2543.

53. Carrasco, L., de Lara, F.C., Gomez-Villamandos, J.C., Bautista, M.J., Villeda, C.J., Wilkinson, P.J. and Sierra, M.A. (1996) The pathogenic role of pulmonary intravascular macrophages in acute African swine fever. Res. Vet. Sci., 61(3): 193-198.

54. Mebus, C.A. and Dardiri, A.H. (1979) Additional characteristics of disease caused by the African swine fever viruses isolated from Brazil and the Dominican Republic. Proc. Annu. Meet. U. S. Anim. Health Assoc., 1(83): 227-239.

55. De Leon, P., Bustos, M.J. and Carrascosa A.L. (2013) Laboratory methods to study African swine fever virus. Virus Res., 173(1): 168-179.

56. Gallardo, C., Fernández-Pinero, J. and Arias, M. (2019) African swine fever (ASF) diagnosis, an essential tool in the epidemiological investigation. Virus Res., 271(10: 197676.

57. Agüero, M., Fernández, J., Romero, L., Sanchez, C., Arias, M. and Sánchez-Vizcaíno J.M. (2003) Highly sensitive PCR assay for the routine diagnosis of African swine fever virus in clinical samples. J. Clin. Microbiol., 41(9): 4431-4434

58. Fernández-Pinero, J., Gallardo, C., Elizalde, M., Robles, A., Gómez, C., Bishop, R., Heath, L., Couacy-Hymann, E., Fasina, O., Pelayo, V., Sole, R.A. and Arias, M. (2013) Molecular diagnosis of African Swine Fever by a new real-time PCR using universal probe library. Transbound. Emerg. Dis., 60(1): 48-58.

59. Pastor, M.J., Arias, M. and Escribano, J.M. (1990) Comparison of two antigens for use in an enzyme-linked immunosorbent assay to detect African swine fever antibody. Am. J. Vet. Res., 51(10): 1540-1543.

60. Gallardo, C., Nieto, R., Soler, A., Pelayo, V., FernándezPinero, J., Markowska-Daniel, I., Pridotkas, G., Nurmoja, I., Granta, R., Simón, A., Pérez, C., Martín, E., FernándezPacheco, P. and Arias, M. (2015) Assessment of African swine fever diagnostic techniques as a response to the epidemic outbreaks in Eastern European Union countries: How to improve surveillance and control programs. J. Clin. Microbiol., 53(8): 2555-2565.

61. Sánchez-Vizcaíno, J.M. (1987) African swine fever diagnosis. In: Becker, Y., editor. African Swine Fever. Martinus 
Nijhoff, Boston, USA. p63-71.

62. Pastor, M.J., Laviada, M.D., Vizcaino, J.M.S. and Escribano, J.M. (1989) Detection of African swine fever virus antibodies by immunoblotting assay. Can. J. Vet. Res., 53(1): 105-107.

63. Dixon, L.K., Islam, M., Nash, R. and Reis, A.L. (2019) African swine fever virus evasion of host defenses. Virus Res., 266(1): 25-33.

64. Frouco, G., Freitas, F.B., Martins, C. and Ferreira, F. (2017) Sodium phenylbutyrate abrogates African swine fever virus replication by disrupting the virus-induced hypoacetylation status of histone H3K9/K14. Virus Res., 242(10): 24-29.

65. Galindo, I., Hernaez, B., Berna, J., Fenoll, J., Cenis, J.L., Escribano, J.M. and Alonso, C. (2011) Comparative inhibitory activity of the stilbenes resveratrol and oxyresveratrol on African swine fever virus replication. Antiviral. Res., 91(1): 57-63.

66. Hakobyan, A., Galindo, I., Nanez, A., Arabyan, E., Karalyan, Z., Chistov, A.A., Streshnev, P.P., Korshun, V.A., Alonso, C. and Zakaryan, H. (2018) Rigid amphipathic fusion inhibitors demonstrate antiviral activity against African swine fever virus. J. Gen. Virol., 99(1): 148-156.

67. Juszkiewicz, M., Walczak, M., Mazur-Panasiuk, N. and Woźniakowski, G. (2019) Virucidal effect of chosen disinfectants against African swine fever virus (ASFV) preliminary studies. Pol. J. Vet. Sci., 22(4): 777-780.

68. Kouam, M.K., Jacouba, M. and Moussala, J.O. (2020) Management and biosecurity practices on pig farms in the Western Highlands of Cameroon (Central Africa). Vet. Med. Sci., 6(1): 82-91.

69. Food and Agriculture Organization. (2010) Good Practices for Biosecurity in the Pig Sector Issues and Options in Developing and Transition Countries. FAO Animal Production and Health Paper No. 169. Food and Agriculture Organization, Rome.

70. Teklue, T., Sun, Y., Abld, M., Luo, Y. and Qiu, H.J. (2020) Current status and evolving approaches to African swine fever vaccine development. Transbound. Emerg. Dis., 67(2): 529-542.

71. Revilla, Y., Perez-Nunez, D. and Richt, J.A. (2018) African swine fever virus biology and vaccine approaches. $A d v$. Virus Res., 100(1): 41-44.

72. Gallardo, C., Sánchez, E.G., Pérez-Núñez, D., Nogal, M., de León, P., Carrascosa, Á.L. and Revilla, Y. (2018a). African swine fever virus (ASFV) protection mediated by NH/P68 and NH/P68 recombinant live-attenuated viruses. Vaccine, 36(19): 2694-2704.

73. Sánchez-Cordón, P.J., Jabbar, T., Berrezaie, M., Chapman, D., Reis, A., Sastre, P. and Dixon, L.K. (2018b). Evaluation of protection induced by immunisation of domestic pigs with deletion mutant African swine fever virus Benin $\triangle \mathrm{MGF}$ by different doses and routes. Vaccine, 36(5): 707-715.

74. Reis, A.L., Abrams, C.C., Goatley, L.C., Netherton, C., Chapman, D.G., Sanchez-Cordon, P. and Dixon, L.K. (2016). Deletion of African swine fever virus interferon inhibitors from the genome of a virulent isolate reduces virulence in domestic pigs and induces a protective response. Vaccine, 34(39): 4698-4705.

75. Reis, A. L., Goatley, L. C., Jabbar, T., Pedro, J., Sanchez-Cordon, P. J., Christopher, L. and Dixon, L. K. (2017b). Deletion of the African swine fever virus gene DP148R does not reduce virus replication in culture but reduces virus virulence in pigs and induces high levels of protection against challenge. J. Virol., 91(24): e01428-17.
76. Monteagudo, P.L., Lacasta, A., López, E., Bosch, L., Collado, J., Pina-Pedrero, S. and Rodríguez, F. (2017). BA $71 \Delta C D 2 v$ : A new recombinant live attenuated African swine fever virus with cross-protective capabilities. J. Virol., 91(21):e01058-17.

77. O'Donnell, V., Risatti, G.R., Holinka, L.G., Krug, P.W., Carlson, J., Velazquez-Salinas, L. and Borca, M.V. (2017). Simultaneous deletion of the 9GL and UK genes from the African swine fever virus Georgia 2007 isolate offers increased safety and protection against homologous challenge. J. Virol., 91(1).

78. Sanford, B., Holinka, L.G., O’Donnell, V., Krug, P.W., Carlson, J., Alfano, M. and Borca, M.V. (2016). Deletion of the thymidine kinase gene induces complete attenuation of the Georgia isolate of African swine fever virus. Virus. Res., 213(1): 165-171.

79. O’Donnell, V., Holinka, L.G., Sanford, B., Krug, P.W., Carlson, J., Pacheco, J.M. and Borca, M.V. (2016). African swine fever virus Georgian isolate harboring deletion of 9GL and MGF360/505 gene is highly attenuated in swine but does not confer protection against parental virus challenge. Virus. Res., 221(1): 8-14.

80. Carlson, J., O'Donnell, V., Alfano, M., Salinas, L., Holinka L.G., Krug, P.W. and Borca, M.V. (2016) Association of the host immune response with protection using a live attenuated African swine fever virus model. Viruses, 8(10): 291-306. doi: 10.3390/v8100291.

81. O'Donnell, V., Holinka, L.G., Gladue, D.P., Sanford, B., Krug, P.W., Lu, X. and Borca, M.V. (2015a). African swine fever virus Georgia isolate harboring deletions of MGF360 and MGF505 genes is attenuated in swine and confers protection against challenge with virulent parental virus. J. Virol, 89(11): 6048-6056.

82. O'Donnell, V., Holinka, L.G., Krug, P.W., Gladue, D.P., Carlson, J., Sanford, B. and Borca, M.V. (2015b). African swine fever virus Georgia 2007 with a deletion of virulence-associated gene 9GL (B119L), when administered at low doses, leads to virus attenuation in swine and induces an effective protection against homologous challenge. J. Virol., 89(16): 8556-8566.

83. King, K., Chapman, D., Argilaguet, J. M., Fishbourne, E., Hutet, E., Cariolet, R. and Takamatsu, H., H. (2011). Protection of European domestic pigs from virulent African isolates of African swine fever virus by experimental immunisation. Vaccine, 29(28): 4593-4600.

84. Martins, C.L.V., Lawman. M.J.P., Scholl, T., Mebus, C.A. and Lunney, J.K. (1993). African swine fever virus specific porcine cytotoxic T-Cell activity. Arch. Virol., 129(1-4): 211-225.

85. Leitão, A., Cartaxeiro, C., Coelho, R., Cruz, B., Parkhouse, R.M., Portugal, F.C. and Martins, C.L. (2001). The non-haemadsorbing African swine fever virus isolate ASFV/NH/P68 provides a model for defining theprotective anti-virus immune response. J. Gen. Virol., 82(3): 513-523.

86. Gallardo, C., Soler, A., Rodze, L., Nieto, R., CanoGómez, C., Jovita Fernandez-Pinero, J. and Arias, M. (2018b). Attenuated and non-haemadsorbing (non-HAD) genotype II African swine fever virus (ASFV) isolated in Europe, Latvia 2017. Trans. Emerg. Dis., 66(3):1399-1404.

87. Lacasta, A., Monteagudo, P.L., Marín, Á.J., Accensi, F., Ballester, M., Argilaguet, J. and Rodríguez, F.L. (2015). Live attenuated African swine fever viruses as ideal tools to dissect the mechanisms involvedin viral pathogenesis and immune protection. Vet. Res., 46(1): 135-151.

\section{$* * * * * * * *$}

